\title{
Changes of Membrane Fluidity in Erythrocytes of Obese Children: A Spin Label Study
}

\author{
GIOVANNA CURATOLA, GIANNA FERRETTI, ENRICO BERTOLI, MARIA DOTTI, \\ EDOARDO BARTOLOTTA, AND PIERLUIGI GIORGI \\ Institutes of Biochemistry and Pediatrics [E.B., P.G.], Faculty of Medicine, Ancona, Italy
}

\begin{abstract}
Red blood cells depend on circulating lipoproteins for the turnover of membrane phospholipids. Thus abnormalities in lipid and lipoprotein metabolism are frequently associated with changes in composition and fluidity of erythrocyte membranes. Using the electron spin resonance technique we studied the physical state of erythrocyte membranes from 15 obese children with a body mass index ranging from 22.8 to $34 \mathrm{~kg} \cdot \mathrm{m}^{-2}$ and slight alterations of plasma lipids. The spin labels used, 5-doxylstearate and 16-doxylstearate, have shown an increase of the order parameter and of the correlation time, respectively. These observations indicate a decrease of fluidity at the surface and in the hydrophobic core of erythrocyte membranes from obese subjects. The results are statistically significant and they are discussed in relation to clinical aspects of childhood obesity. Studies on erythrocyte membrane molecular organization could represent a sensitive way to find out small metabolic alterations hardly detectable with compositional studies. (Pediatr Res 22:141-144, 1987)
\end{abstract}

\section{Abbreviations}

LPL, lipoprotein lipase

LCAT, lecithin-cholesterol acyl transferase

ESR, electron spin resonance

BMI, body mass index

5-NS, 5-doxylstearate

16-NS, 16-doxylstearate

LDL, low-density lipoproteins

HDL, high-density lipoproteins

$\mathrm{RBC}$, red blood cells

Several studies on metabolic and functional alterations in obesity are limited to obese adults; less attention has been devoted to the pediatric obese subjects. In adult obese patients modifications of the activity of the LPL (1) and of the LCAT (2) suggest the hypothesis that obesity could be associated with alterations of the lipoprotein metabolism.

It is known that in certain specific pathological states, inborn errors of metabolism and/or dietary or hormonal disturbances are associated with changes in the surface of lipids of circulating lipoproteins and several lines of evidence correlate these changes with abnormalities in the lipids of erythrocyte membrane (3-7).

Because the molecular organization of the erythrocyte membrane is known in detail, it is possible to correlate changes in membrane composition with modifications in membrane fluid-

Received September 8, 1986; accepted February 19, 1987.

Correspondence should be addressed to Prof. Giovanna Curatola, Istituto di Biochimica, Facoltà di Medicina e Chirurgia, Via Ranieri, 60131 Ancona, Italy.

Supported by a grant from Regione Marche, Ricerca Sanitaria Finalizzata, n. $21322-5-1985$ ity, moreover it is well known that membrane fluidity affects membrane-bound enzyme activities $(8,9)$. A reduced level of erythrocyte membrane tocopherol (10) which could explain the erythrocyte sensitivity to peroxidative damage, a lower concentration of insulin receptors (11), and a reduced $\mathrm{Na}^{+} \mathrm{K}^{+}$pump (12) have been shown in erythrocytes of obese children. However until now there is no evidence for their direct or indirect involvement in the pathogenesis of obesity.

The possible correlations between obesity and membrane physical state were studied with the purpose to bring forward a working model in which erythrocyte membrane represents a final system reflecting and amplifying metabolic disorders. To this aim we have studied membrane fluidity using the ESR technique (13-17). Membrane fluidity is strictly related to membrane composition and structure. The ordinary metabolic and hematological laboratory parameters were also determined and the possible relationships between functional and molecular alterations were investigated.

\section{MATERIALS AND METHODS}

Patients. Fifteen obese children (11 females and four males; age range 6-14 yr) who had no sign of endocrine or genetic disease and seven normal weight children (four females, three males; similar age range) were studied. All the examined subjects were from the same region of Italy with similar nutritional habits. The BMI (weight in $\mathrm{kg}$ divided by square of height in $\mathrm{m}$ ) taken as measure of obesity (18) ranged from $22.8-34 \mathrm{~kg} \cdot \mathrm{m}^{-2}$ in the obese subjects and from $14.6-22.2 \mathrm{~kg} \cdot \mathrm{m}^{-2}$ in the controls. Appropriate informed consent was obtained for this study. Physical characteristics of obese and control children are given in Table 1.

Preparation of erythrocyte membranes. Five $\mathrm{ml}$ of blood were drawn from each subject after a 12-h overnight fast and placed in heparinized tubes. Erythrocytes were washed three times with isotonic saline $(0.15 \mathrm{M} \mathrm{NaCl}, 10 \mathrm{mM}$ Tris- $\mathrm{HCl} \mathrm{pH} \mathrm{7.4)}$ and the buffy coat and plasma were removed each time. Erythrocyte membranes were prepared by hemolizing the washed erythrocytes in $5 \mathrm{mM}$ phosphate buffer $\mathrm{pH} 8$, following the method of Steck and Kant (19). Membrane protein content was estimated by the method of Lowry et al. (20) using bovine serum albumin as a standard.

Erythrocyte spin labeling and ESR measurements. The membrane fluidity was studied by means of the ESR technique with two spin labels: 5-NS and 16-NS. These labels which have a nitroxide radical ring at the 5 th and 16 th carbon position (Fig. 1) probe the physical state of the membrane surface and hydrophobic core, respectively (Fig. 1). The ESR technique has been well established as a valuable tool in the study of both biological and model membranes. The labels purchased from Syva Co (Palo Alto, CA) were dissolved in absolute ethanol at a concentration of $10 \mathrm{mM}$ and kept at $-20^{\circ} \mathrm{C}$.

Incorporation of the labels into the membranes was accom- 
Table 1. Physical characteristics of obese and control subjects $($ mean $\pm S D)$

\begin{tabular}{lccc}
\hline & & & Age \\
Subjects & Sex & $(\mathrm{yr})$ & $\begin{array}{c}\mathrm{BMI} \\
\left(\mathrm{kg} \times \mathrm{m}^{-2}\right) \\
(\mathrm{range})\end{array}$ \\
\hline Controls & $3 \mathrm{M}$ & $12 \pm 1$ & $18 \pm 3$ \\
& $4 \mathrm{~F}$ & & $(14.6-22.2)$ \\
Obese & $4 \mathrm{M}$ & $11 \pm 3$ & $28.21 \pm 3^{*}$ \\
& $11 \mathrm{~F}$ & & $(22.8-34)$ \\
\hline
\end{tabular}

$* p<0.001$.<smiles>CCCCCCCCCCCCCC1(CCCC(=O)O)OCCN1C(=O)N1CCOC1(CC)CCCCCCCCCCCCCCCC(=O)O</smiles>

5 NS

16 NS

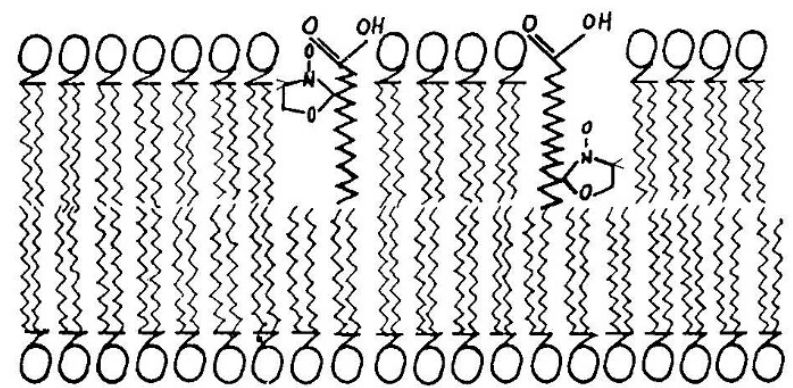

Fig. 1. Chemical formulae and localization in biological membranes of 5-NS and 16-NS.

plished as described elsewhere (13). Ethanol was evaporated under a nitrogen stream and the samples were incubated overnight at $4^{\circ} \mathrm{C}$. A probe to phospholipid ratio of 1:100 was used. ESR studies were performed with a Varian E-4 spectrometer (microwave frequency $9.1 \mathrm{Ghz}$; modulation amplitude 1.6 Gauss; time constant $0.5 \mathrm{~s}$ ).

The spin labels embedded in biological membranes exhibit their freedom of anisotropic motion in conformity with the position of the nitroxide ring of the alkyl fatty acid chain. The anisotropic motion reflects the molecular motion of phospholipids and depends on order and fluidity. The spectra of 5-NS and of 16-NS embedded in erythrocyte membranes are shown in Figure $2 a$ and $b$, respectively.

The observed values of the outer $\left(2 \mathrm{~T}_{||}\right)$and inner $(2 \mathrm{~T} \perp)$ hyperfine splitting (in Gauss) were used to calculate the order parameter ( $\mathrm{Sn}$ ) for 5-NS according to the following equation (16):

$$
\mathrm{Sn}=0.568 \frac{\mathrm{T}_{11}-\mathrm{T}_{+}}{\mathrm{a}^{\prime}} \quad \text { where } \mathrm{a}^{\prime}=(1 / 3)\left(\mathrm{T}_{11}+2 \mathrm{~T}_{\iota}\right)
$$

where $a^{\prime}$ is a measure of the polarity, which decreases with decreasing polarity.

For 16 NS the pseudoisotropic motion can be described by the empirical parameter $h_{0} / h_{-1}$ which is the ratio between the mid-field height $\left(\mathrm{h}_{0}\right)$ and the high field height $\left(\mathrm{h}_{-1}\right)$; however results are also presented using the correlation time $\left(\tau_{\mathrm{c}}\right)$ calculated according to Kivelson (21).

$$
\tau_{c}=6.5 \times 10^{-10} \mathrm{w}_{0}\left[\left(\mathrm{~h}_{0} / \mathrm{h}_{-1}\right)^{1 / 2}-1\right]
$$

where $w_{0}$ is the line width.

The constant $\mathrm{k}=6.5 \times 10^{-10} \mathrm{~s}$ is dependent on the anisotropic hyperfine coupling values and the g-tensor terms when the correlation time $\tau_{\mathrm{c}}$ is greater than $10^{-9} \mathrm{~s}(22)$.
Although a direct comparison between Sn (for 5-NS) and $\tau_{\mathrm{c}}$ (for 16-NS) is not possible, both values are used independently to evaluate membrane fluidity at the surface and in the hydrophobic core, respectively. A decrease in membrane fluidity is associated with greater values of outer hyperfine splitting $\left(2 \mathrm{~T}_{\mid 1}\right)$, order parameter $(\mathrm{Sn})$, peak height ratio $\left(\mathrm{h}_{0} / \mathrm{h}_{-1}\right)$, and correlation time $\tau_{\mathrm{c}}$.

Plasma lipids. Total cholesterol, triglycerides and total lipids were measured by the methods of Allain et al. (23), Bucolo and David (24), and Zoellner and Kirsch (25), respectively. Plasma free fatty acids were measured according to Laurell and Tibbling (26). Lipoprotein analysis was performed using cellulose acetate electrophoresis (27).

Statistics. All results are expressed as means \pm SEM if not otherwise indicated. Statistical differences between data from

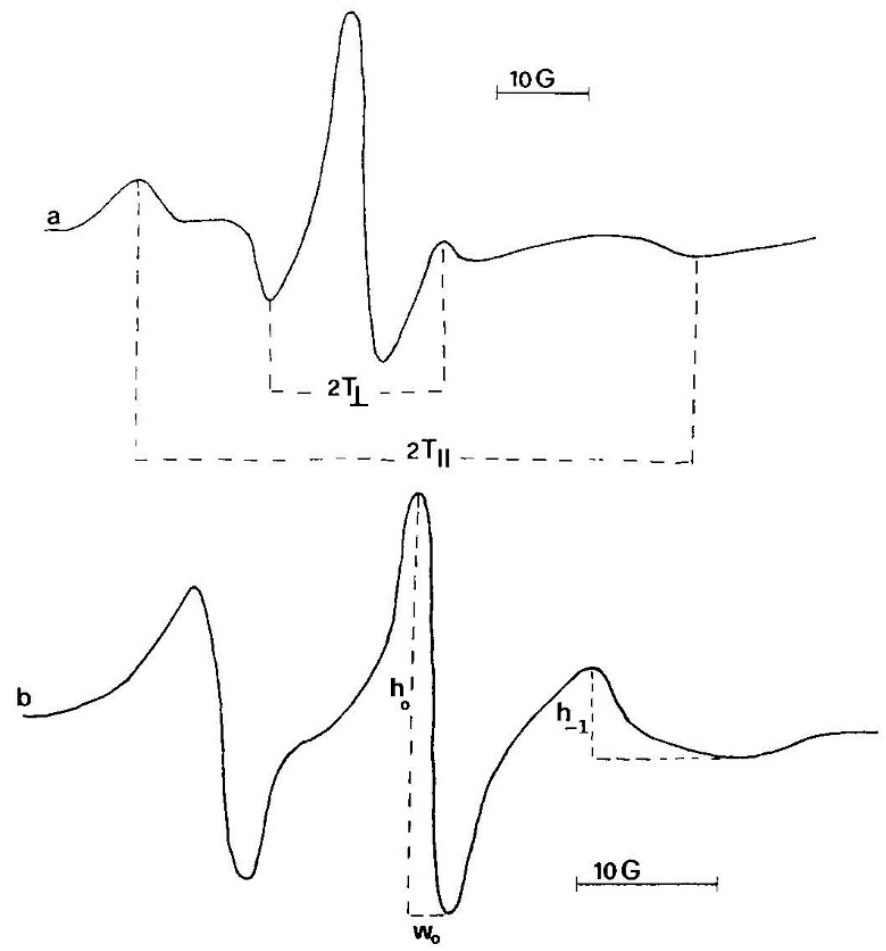

Fig. 2. ESR spectra of 5-NS (a) and 16-NS $(b)$ in erythrocyte membranes.

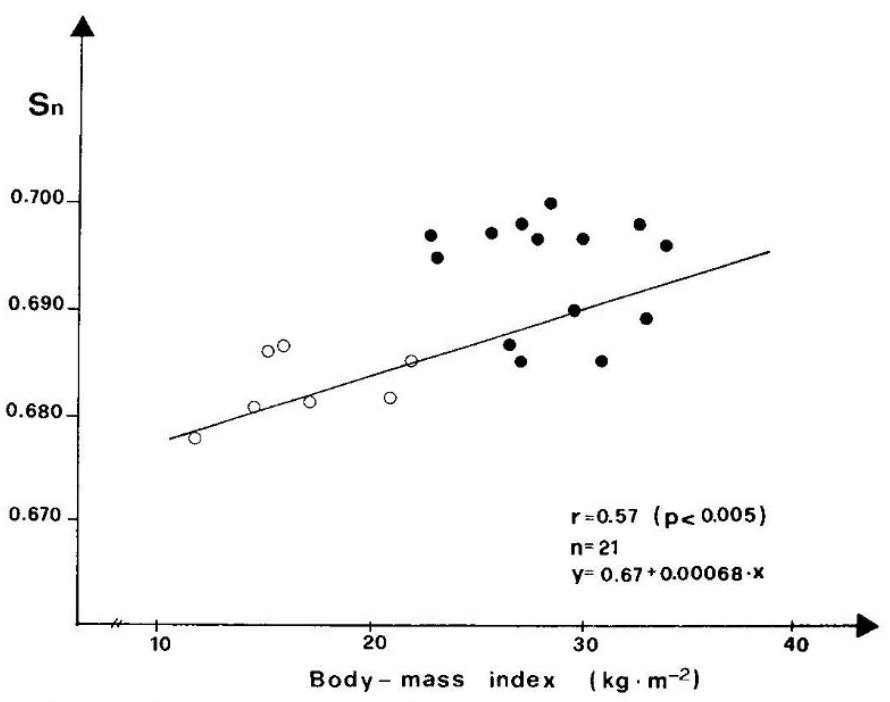

Fig. 3. Correlation between the order parameter (Sn) of 5-NS and BMI in controls $(O)$ and obese $(\bullet)$ subjects. 


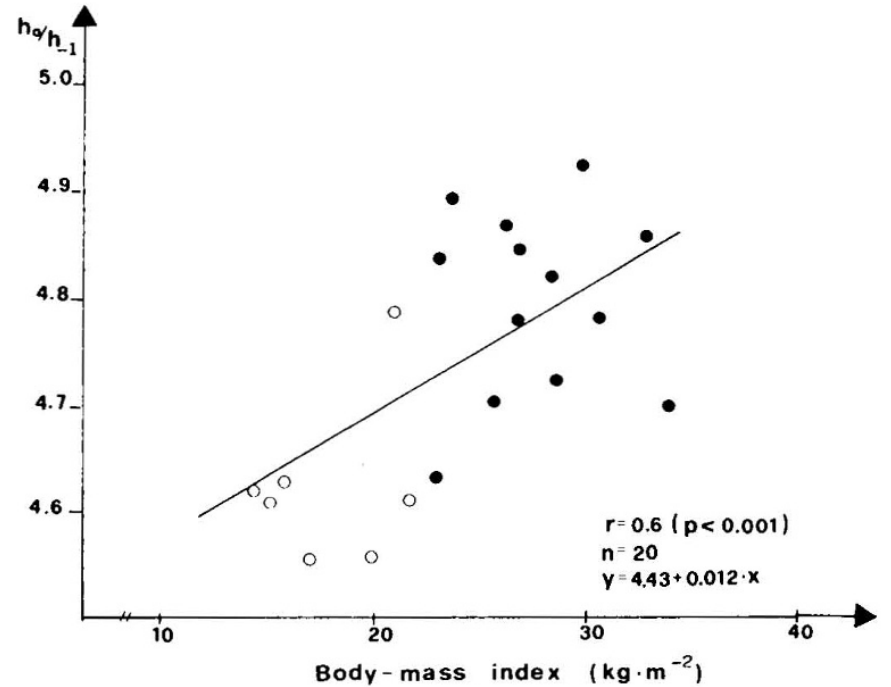

Fig. 4. Correlation between the peak height ratio $\left(h_{0} / h_{-1}\right)$ of $16-N S$ and $\mathrm{BMI}$ in controls $(\mathrm{O})$ and obese $(\Theta)$ subjects.

Table 2. Plasma lipid analysis in obese children and controls (mean \pm SEM)

\begin{tabular}{lcc}
\hline & Controls & Obese \\
\hline Cholesterol $\left(\mathrm{mg} \mathrm{dl}^{-1}\right)$ & $160 \pm 23$ & $159 \pm 16$ \\
Triglycerides $\left(\mathrm{mg} \mathrm{dl}^{-1}\right)$ & $66 \pm 3$ & $113 \pm 8^{*}$ \\
Total lipids $\left(\mathrm{mg} \mathrm{dl}^{-1}\right)$ & $561 \pm 26$ & $612 \pm 22$ \\
Lipoproteins LDL (\%) & $55 \pm 3$ & $63 \pm 3^{*}$ \\
HDL (\%) & $44 \pm 3$ & $36 \pm 1^{*}$ \\
LDL/HDL ratio & $1.33 \pm 0.1$ & $1.83 \pm 0.1^{*}$ \\
Free fatty acids (mg dl $\left.{ }^{-1}\right)$ & $11 \pm 0.9$ & $15 \pm 1.5$ \\
\hline
\end{tabular}

${ }^{*} p<0.05$.

obese and nonobese subjects were determined by the Student's $t$ test. Linear regression analysis was used to assess the degree of correlation between BMI and fluidity parameters.

\section{RESULTS}

The physical characteristics of the controls and the obese patients studied are summarized in Table 1 . The BMI $\left(\mathrm{kg} \cdot \mathrm{m}^{-2}\right)$ was significatively $(p<0.001)$ higher in the obese subjects $(28.21$ \pm 3 ) with respect to the controls $(18 \pm 3)$. No significant age difference was observed between the two groups.

Plasma lipids. Plasma total lipids and free fatty acids (Table 2) were slightly increased in obese patients when compared with normal controls as previously observed $(10,28)$. There was no significant difference in the plasma total cholesterol values. In the obese patients we observed a significant increase in plasma triglycerides $(p<0.05)$ although the mean value is in the normal range (Table 2). These results are opposite to those of Kitagawa et al. (10) and are probably due to the different environment and ethnic origin of the examined population. In our patients it is evident that there is an increase in LDL and a decrease in HDL levels with a consequent significant increase of the LDL/HDL ratio $(p<0.05)$ in relation to the normal value (Table 2 ).

Membrane fluidity. The ESR spectra of 5-NS in erythrocyte membranes of obese subjects have shown an increase in hyperfine splitting $2 \mathrm{Tl}$ and in order parameter $(\mathrm{Sn})$ in respect to the controls (Table 3 ). The increase of the order parameter $\mathrm{Sn}$ was highly significant with $p<0.001$ indicating a decrease of the probe amplitude of motion about the average orientation. A significant increase either of the peak height ratio $\left(\mathrm{h}_{0} / \mathrm{h}_{-1}\right)(p<$ $0.05)$ or the motion parameter of the probe 16-NS $(p<0.05)$ indicates a decrease of fluidity also in the hydrophobic core of the membrane (Table 4). It is of interest to stress that the SEM of ESR measurements are extremely small so that the difference in the mean values for the two groups are highly significant.

The results show that in the obese subjects there is an increase of the order in the surface and more restricted mobility in the hydrophobic core indicating a decrease of membrane fluidity. Relative to the controls every obese subject studied showed similar modifications of the ESR parameters for both the spin probes used (Table 5) suggesting that the erythrocyte membrane could be a suitable model in the study of obesity in childhood. The increments, expressed as percent increase calculated for each obese compared with the control means shown in Tables 3 and 4 , ranged between 0.4 to 2.6 for $\mathrm{Sn}$ and between 0.5 and 6.9 for $h_{0} / h_{-1}$. The relevance of the changes in ESR parameters $S n$ and $h_{0} / h_{-1}$ to the pathophysiology of the obese state is supported by the positive correlation with the BMI (Figs. 3 and 4).

\section{DISCUSSION}

In the erythrocyte membranes of obese patients, we observed a decrease of fluidity by means of the spin label method. The alterations in the physical state of RBC membrane were evident even in the absence of remarkable changes in plasma lipids and lipoproteins. The positive correlation between the BMI and the erythrocyte membrane physical state, suggests that the decrease in membrane fluidity could be considered as a parameter which

Table 3. Outer hyperfine splitting $\left(2 T_{11}\right)$ and order parameter (Sn) for 5-NS in erythrocyte membranes from obese and controls (mean $\pm S E M)$

\begin{tabular}{lrcc}
\hline & $n$ & $2 \mathrm{~T}_{11}$ & $\mathrm{Sn}$ \\
\hline Controls & 7 & $56.86 \pm 0.09$ & $0.682 \pm 0.001$ \\
Obese & 15 & $57.18 \pm 0.10$ & $0.692 \pm 0.001^{*}$ \\
\hline
\end{tabular}

$* p<0.001$.

Table 4. Peak height ratio $\left(h_{0} / h_{-1}\right)$ and motion parameter $\left(\tau_{c}\right)$ of 16-NS in erythrocyte membranes from obese and controls (mean \pm SEM)

\begin{tabular}{lrll}
\hline & $n$ & \multicolumn{1}{c}{$\mathrm{h}_{0} / \mathrm{h}_{-1}$} & $\tau_{\mathrm{c}}\left(\mathrm{s} \times 10^{-10}\right)$ \\
\hline Controls & 7 & $4.64 \pm 0.07$ & $18.22 \pm 0.08$ \\
Obese & 15 & $4.77 \pm 0.03^{*}$ & $19.07 \pm 0.26^{*}$ \\
\hline
\end{tabular}

${ }^{*} p<0.05$.

Table 5. BMI and values of nitroxide spectral parameters of obese patients*

\begin{tabular}{llc}
\hline BMI & $\mathrm{Sn}$ & $\mathrm{h}_{0} / \mathrm{h}_{-1}$ \\
\hline 22.8 & 2.2 & 0.5 \\
23 & 2 & 5.2 \\
23.5 & 0.5 & 6.3 \\
25.6 & 2.2 & 1.9 \\
26.5 & 0.4 & 5.6 \\
26.6 & 0.7 & 5.2 \\
27.1 & 2.4 & 3.7 \\
27.8 & 2.2 & 4.5 \\
28.5 & 2.6 & 2.4 \\
29.6 & 1.2 & 6.9 \\
30 & 2.2 & 3.9 \\
30.2 & 0.4 & 3.7 \\
32.6 & 2.6 & 4.5 \\
32.9 & 2.4 & 5.2 \\
34 & 2 & 1.9 \\
\hline
\end{tabular}

* Values of the parameters $S n$ for $5 N S$ and $h_{0} / h_{-1}$ for $16-N S$ are expressed as percent increase calculated for each obese compared with control means shown in Tables 3 and 4. 
characterizes the modifications present in the RBC in obesity.

Mammalian RBC lack the ability to synthesize lipids de novo (29) so that the cholesterol content and phospholipid composition which influence membrane fluidity depend on the exchange with the plasma lipoprotein surface. This mechanism serves adaptive and homeostatic roles under normal conditions and alterations in lipoprotein structure could lead to abnormalities in the red cell lipid composition as shown in type IV hypertriglyceridemia and in LCAT deficiency (5). It has been shown that abnormal behavior of RBC is detectable even when only $0.5-$ $1 \%$ of the original membrane phospholipids have been substituted with desaturated species (30). Furthermore, in vivo the survival of cells with this type of modified composition is reduced and some phospholipids substitutions even cause instantaneous removal of erythrocytes from the circulation. These observations suggest that the erythrocyte membrane responds to small variations in plasma lipids with changes in its own composition and physical state.

Various membrane functions such as permeability (31), activities of bound enzymes (32), and hormone receptor functions (33) are modulated by membrane fluidity as a consequence of the role of lipid in controlling optimal conformation of membrane proteins (34). The relationship between pathological manifestations of obesity and alterations in membrane fluidity and hence in membrane functions clearly deserves further investigation.

The results presented herein demonstrate that studies of the erythrocyte membrane by the ESR probe technique detect small modifications in the molecular organization of the membrane which nevertheless have major consequences in terms of its rigidity and fluidity.

\section{REFERENCES}

1. Hamosh M, Hamosh P 1983 Lipoprotein Lipase: its physiological and clinical significance. In: Baum H, Gergely J (eds) Molecular Aspects of Medicine. Pergamon Press, Oxford, pp 248-252

2. Dobiasovà M 1983 Lecithin: cholesterol acyltransferase and the regulation of endogenous cholesterol transport. In: Paoletti R, Kritchevsky D (eds) Advances in Lipid Research. Academic Press, New York, pp 107-185

3. Cooper RA 1977 Abnormalities of cell-membrane fluidity in the pathogenesis of disease. Semin Med Beth Israel Hosp 297:371-377

4. Owen JS 1981 Plasma lipoproteins and cellular metabolism. Nature 292:196

5. Owen JS, McIntyre N, Gillett MPT 1984 Lipoproteins cell membrane and cellular functions. Trends Biochem Sci 5:238-242

6. Kamada T, Otsuji S 1983 Lower levels of erythrocyte membrane fluidity in diabetic patients. A spin label study. Diabetes 32:585-591

7. Cooper RA, Durocher JR, Leslie MH 1977 Decreased fluidity of red cell membrane lipids in abetalipoproteinemia. J Clin Invest 60:115-121

8. Lenaz G, Curatola G, Parenti Castelli G 1982 The role of lipid fluidity in the structure and function of heart mitochondrial membranes. In: Caldarera CM, Harris P (eds) Advances in Studies on Heart Metabolism. CLUEB, Bologna, pp 15-23

9. Pezzoli C, Fiorini RM, Curatola G, Stramentinoli G 1983 S-adenosylmethionine protects against erythrocyte membrane alterations induced in rabbits, by cholesterol-rich diet. Pharmacol Res Commun 15:785-795

10. Kitagawa M, Nakagawa S, Mino M 1983 Influence of plasma lipids and adiposity on red blood cell tocopherol level. Eur J Pediatr 140:238-243

11. Kappy M, Plotnick L 1981 Erythrocyte insulin binding in obese children and adolescents. J Clin Endocrinol Metab 51:1440-1446

12. Dianzani I, Urbino A, Cerutti F, Boero R, Guarena C, Quarello F 1985 Studio cinetico della pompa $\mathrm{Na}^{+}, \mathrm{K}^{+}$negli eritrociti di bambini obesi. Proceedings 3rd Cong. Naz. Soc. Ital. Pediatria Preventiva e Sociale-Nipiologia, Minerva Med p 200(abstr)

13. Lenaz G, Curatola G, Mazzanti L, Zolese G, Ferretti G 1983 Electron spin resonance studies of the effects of lipids on the environment of proteins in mitochondrial membranes. Arch Biochem Biophys 223:369-380

14. Bertoli E, Masserini M, Sonnino S, Ghidoni R, Cestaro B, Tettamanti G 1981 Electron paramagnetic resonance studies on the fluidity and surface dynamics of egg phosphatidylcholine vesicles containing gangliosides. Biochim Biophsy Acta 467:196-202

15. Leterrier F, Lamas E, Daveloose D, Viret J, Rochette J, Schapira J 1984 A spin label study of the erythrocyte membrane in mothers and sisters of patients suffering from Duchenne muscular dystrophy. Clin Chim Acta 143:99-108

16. Seelig J 1971 Anisotropic motion in liquide crystalline structures. In: Berliner LJ (ed). Spin Labeling, Theory and Applications. Academic Press, New York, pp 373-400

17. Henry SA, Keith AD 1971 Membrane properties of saturated fatty acid mutants of yeast revealed by spin labels. Chem Phys Lipids 7:245-265

18. Keys A, Fidanza F, Karvonen MJ, Kimura N, Taylor HL 1972 Indices of relative weight and obesity. J Chronic Dis 25:329-333

19. Steck TL, Kant JA 1974 Preparation of impermeable ghosts and inside out vesicles from human erythrocyte membranes. In: Colowick SP, Kaplan NO (eds) Methods in Enzymology. Academic Press, London, pp 172 173

20. Lowry OH, Rosebrough NJ, Farr AL, Randall RJ 1951 Protein measurement with the folin phenol reagent. J Biol Chem 193:265-275

21. Kivelson D, 1960 Theory of ESR linewidths of free radicals. J Chem Phys 33:1094-1106

22. Eletr S, Inesi G 1972 Phase changes in the lipid moieties of sarcoplasmic reticulum membranes induced by temperature and protein conformational changes. Biochim Biophys Acta 290:178-185

23. Allain CC, Poon LS, Chan CS 1974 Enzymatic determinations of total serum cholesterol. Clin Chem 20:470-475

24. Bucolo G, David H 1973 Quantitative determinations of triglycerides by the use of enzymes. Clin Chem 19:476-482

25. Zoellner B, Kirsch Z 1962 Ueber die quantitative Bestimmung von Lipoiden (Mikromethode) mittels der naturalischen Lipoiden (allen bekannten Plasmalipoiden) gemeinsamen sulfophosfovanillin Reaktion. Z Ges Exp Med 135:545-550

26. Laurell S, Tibbling G 1967 Colorimetric microdetermination of free fatty acids in plasma. Clin Chim Acta 16:57-62

27. Chin MH, Blankhenhorn DH 1968 Separation and quantitative analysis of serum lipoproteins by means of electrophoresis cellulose acetate. Clin Chim Acta 20:305-311

28. Molnar D, Varga P, Rubecz I, Hamar A, Mestyan J 1985 Food-induced thermogenesis in obese children. Eur J Pediatr 144:27-31

29. Marks PA, Gellhorn A, Kidson C 1960 Lipid synthesis in human leucocytes, platelets and erythrocytes J Biol Chem 235:2579-2583

30. Jos AS, Op den Kamp, Roelofsen B, Van Deenen LML 1985 Structural and dynamic aspects of phosphatidylcholine in the human erythrocyte membrane. Trends Biochem Sci 8:320-323

31. Gier JD, Mandersloot JG, Van Deenen LLM 1968 Lipid composition and permeability of liposomes Biochim Biophys Acta 150:666-675

32. Mc Murchie EJ, Raison JK 1979 Membrane lipid fluidity and its effect on the activation energy of membrane-associated enzymes Biochim Biophys Acta 554:364-374

33. Luly P, Shinitzky M 1979 Gross structural changes in isolated liver cell plasma membranes upon binding of insulin. Biochemistry 18:445-450

34. Lenaz G 1978 The role of lipids in the structure and function of membranes. In: Roodyn DB (ed) Subcellular Biochemistry. Plenum Press, New York, pp 233-343 